\title{
Analysis of Influencing Mechanism of Banking Market Structure on Industrial Structural Upgrading
}

\author{
Wenxuan Pan \\ College of Economics, Jinan University, Guangzhou, China \\ Email:642876578@qq.com
}

How to cite this paper: Pan, W.X. (2017) Analysis of Influencing Mechanism of Banking Market Structure on Industrial Structural Upgrading. Open Journal of Social Sciences, 5, 51-58.

https://doi.org/10.4236/jss.2017.54005

Received: March 7, 2017

Accepted: April 16, 2017

Published: April 19, 2017

Copyright $\odot 2017$ by author and Scientific Research Publishing Inc. This work is licensed under the Creative Commons Attribution International License (CC BY 4.0).

http://creativecommons.org/licenses/by/4.0/

c) (i) Open Access

\begin{abstract}
The change of banking market structure may finally influence of development of various industries via guiding the allocation of capital resources among industries. Based on panel data model and SYS-GMM estimation, this paper surveyed the influence of change of Chinese banking structure on industrial structural adjustment and then further explored the influencing mechanism in it. The result showed that, under overall samples, the increased proportion of non-state-owned banks in China not only is beneficial to the reasonable development of industrial structure, but also can promote advanced development; banking structure will influence the rationalization as well as optimization of Chinese industrial structure through technological progress and financing restraint looseness. The influencing mechanism of technological progress is positive while the influencing mechanism of financing restraint looseness on rationalization as well as optimization is in the opposite.
\end{abstract}

\section{Keywords}

Banking Market Structure, Industrial Structural Adjustment, Technological Progress, Financing Restraint Looseness

\section{Introduction}

With respect to the relationship between the banking market structure and industrial structural upgrading, some of the literatures concluded a positive relationship between industry concentration (or financial agglomeration) and industrial structural upgrading; e.g. Sun Jing and Li Hanshuo (2012) [1] found that financial agglomeration accelerated of industrial structural upgrading in eastern and western regions of China, and the function of the bank agglomeration is the most obvious. The test made by Liu Peisen and Yin Xiguo (2015) [2] discovered 
that the spatial spillover effect of banking market structure, financial deepening and industrial structural upgrading, and the increased market share of stateowned commercial banks all promoted industrial structural upgrading.

More scholars summarized that, industry concentration is in negative correlation with industrial structural upgrading, increased the proportion of stateowned banks goes against industrial restructuring and upgrading; for example, Liu Peisen (2014) [3] discovered that the increase of deposit and loan market share in small and medium-sized financial institutions will positively promote the optimization of industrial structure, but the mismatch between banking market structure and economic structure impede the optimization of industrial structure. Based on model deduction, Gong Qiang et al. (2014) [4] pointed out that the banking system dominated by four major state-owned banks still cannot fully meet the fund demands of small and medium-sized enterprises; on the contrary, to develop local small and medium-sized banks can better solve the financial support of small and medium-sized enterprises, and promote industrial as well as financial structural optimization. The results from Peng Yuwen et al. (2013) [5] showed that the overall concentration of bank deposits and loan is obvious in negative correlation with economic growth, which will indirectly and negatively transfer to industrial structural upgrading. Liu Ning (2014) [6] found that the enhancement of bank concentration in Guangdong play a long-term negative impact on the adjustment of industrial structure.

It has seen from the literature review results, in the existing about the relationship between structure and industrial structure upgrade of the bank of the empirical literature at home and abroad, there hasn't been consistent conclusion, Combining with the above, this paper mainly do the following: one is the test of banking market structure effect on the upgrading of industrial structure. Two discuss the influences of relationship between structure and industrial structure upgrade of the bank system from the perspective of technological progress and financial constraints to reduce.

This article is divided into five chapters:

Chapter one: Introduction. This chapter is about summarizing the literature of the relationship about bank market structure and economic growth of foreign and domestic and give a brief review about it.

Chapter two: Research Design and Selection of Variables. At first, this chapter builds the econometric model for the purpose of this paper and goes on to variable selection sample selection and data collection, and has carried on the simple statistics to variable description. Use of panel system of SYS-GMM examined bank market structure effects on industrial structure upgrade

Chapter three: Measure Regression Result and Analysis. based on chapter two, this chapter specifically selected and introduced the bank market structure affects the upgrading of industrial structure in two way: Technological progress and reduce the financial constraints. Then according to the setting model of bank market structure through technological progress and financial constraints to reduce influence industrial structure upgrade, and the explanation is given. 
Chapter four: Main conclusions and recommendations of this chapter discuss the main research conclusion, and give relevant policy recommendations.

\section{Research Design and Selection of Variables}

\subsection{Model Building and Estimation Method}

This paper mainly analyzes the influence of market structure of Chinese banking industry on industrial structure from the perspective of demonstration. In this paper, the panel data at provincial level is applied to firstly establish the following model:

$$
u_{i s_{i t}}=\alpha+\beta_{1} \times \text { cluster }_{i t}+\gamma \times X_{i t}+\varepsilon_{i t}
$$

In formulas (1), $u i s_{i t}$ is the industrial structure of number $i$ province in $t$ th year, cluster $_{i t}$ is the banking market structure (banking industry concentration degree) of number $i$ province in $t$ th year, $X$ is control variable and $\alpha$ is constant term, $i=1, \cdots, N, t=1, \cdots, T$.

At present, the literatures on banking structure and industrial structural upgrading mostly study the relationship between these two while not discussing the mechanism that may affect the relationship between these two. This paper considers that as financial intermediary, bank mainly plays positive role in industrial structural upgrading from two aspects: one is the technical level, relatively speaking, non state-owned banks are more willing to put loan to emerging strategic industry and independent entrepreneurial project because these industries are more conducive to the progress of social technology. Therefore, the effect of bank loans on the industrial structure is more likely to be caused by technological progress. On the other hand, bank's acceleration of the loan to department in need of capital can promote these units to solve financial needs, help reduce overall social financing constraints. Therefore, this paper chooses two factors of social technological progress and social financing constraints to analyze whether the banking structure affects the rationalization and optimization of industrial structure through these two mechanisms.

$$
\begin{aligned}
& \text { uis }_{i t}=\alpha+\beta_{1} \times \text { cluster }_{i t}+\delta \times\left(\text { tech }_{i t} \times \text { cluster }_{i t}\right)+\gamma \times X_{i t}+\varepsilon_{i t} \\
& \text { uis }_{i t}=\alpha+\beta_{1} \times \text { cluster }_{i t}+\delta \times\left(\text { fin }_{i t} \times \text { cluster }_{i t}\right)+\gamma \times X_{i t}+\varepsilon_{i t}
\end{aligned}
$$

In formulas (2) and (3), tech ${ }_{i t}$ is the measurement index of social technological progress, $\mathrm{fin}_{i t}$ is the measurement index of social financing constraints (or comprehended as financial development); the definitions of other variables is the same as formula (1).

According to the above literature review, some scholars concluded that the process of industrial structural upgrading might in turn affect banking market structure; that is to say, to the entire model, it is not purely exogenous but exists the issue of endogenous system, so this paper selected System GMM method to estimate the model.

\subsection{Selection of Variables}

1) Dependent Variable: Industrial Structure 
The previous literatures researching industrial structural upgrading considered industrial structural upgrading as a whole; Gan Chunhui pointed out that, in the dynamic view, the change of industrial structure should include two aspects, which are the rationalization and optimization; these two aspects together can be referred to as the authentic industrial structural upgrading. Referring to the measurement formulas of rationalization and optimization of industrial structure, this paper calculated the two indexes.

Rational industrial structure refers to the aggregation quality among tertiary industries, which can be measured by using Theil index:

$$
\text { uis_tl }=\sum_{i=1}^{n}\left(\frac{Y_{i}}{Y}\right) \ln \left(\frac{Y_{i}}{L_{i}} / \frac{Y}{L}\right)
$$

whereas, $Y_{i}$ is the added value of $i$ th industry, $L_{i}$ is the employment figures of $i$ th industry, $Y$ and $L$ are total added value and general employment figures. The closer the index value to 0 , the more rationality of industrial structure and employment structure will be. Since formula (5) is an inverse index, it is easier to express subsequently in empirical model analysis; after obtaining this index value through calculation, apply reciprocal process to this index, which is:

$$
\text { uis_tl }=1 / \sum_{i=1}^{n}\left(\frac{Y_{i}}{Y}\right) \ln \left(\frac{Y_{i}}{L_{i}} / \frac{Y}{L}\right)
$$

The optimization of industrial structure generally means the industrial structural upgrading in a narrow sense, which is the process of transferring from the primary industry to the third industry of the industry in highest ratio in national economy. This paper adopted the ratio of the output value of third industry and second industry to measure the text of optimization of industrial structure.

$$
\text { uis_ts }=Y_{3} / Y_{2}
$$

2) Independent variable:

Banking market structure cluster generally refers to the concentration of each bank distribution in banking industry. In 2014, the deposits of four major state-owned banks in the banking sector accounted for $67.63 \%$, the proportion of assets was 63.85\%; but according to the development trend, the proportion of state-owned banks presented downtrend, namely bank market structure adjustment. This paper hypothesized that, compared with state-owned banks, the development of non state-owned banks could better accelerate industrial structural upgrading, so this paper mainly measured by using the proportion of non-stateowned banks in the banking industry, the index is defined as:

Banking market structure cluster $=$ Total amount of loans from non stateowned banks/total amount of loans from regional banks.

Hereinto, state-owned banks refer to ICBC, CCB, Bank of China and ABC.

3) Control variable: This paper selected three indexes of urbanization rate, market openness and per capita consumption level

Urbanization rate urban. The population urbanization rate is used to measure urbanization level, which is equal to the ratio of urban resident population to 
regional total population.

Market openness open: The ratio of total volume of foreign trade to GDP is applied to measure the degree of market openness

Per capita consumption level ln com : the logarithm value of per capita consumption level of urban residents is adopted to measure the index

4) Mechanism variable

a) Technological progress tech. At present, different scholars use different metrics; e.g. Dong Li [7] expressed narrow technical progress with the growth rate of total factor productivity (also known as the Solow residual value), Sheng Xin [8] measured through using the input of number of patent applications and research funds; besides, some other scholars measured based on per capita output, production rate and other indexes. Referring to the method of Dong Li, this paper measured technological progress with the growth rate of total factor productivity; the specific calculation process is:

$$
Y g_{i t}=T F P+\alpha \times K g_{i t}+\beta \times L g_{i t}
$$

The equation is derived based on Cobb-Douglas production function, among which $Y g_{i t}$ is actual output growth rate, $K g_{i t}$ is actual capital growth rate, $L g_{i t}$ is labor force growth rate, TFP represents total factor productivity, which is the index measuring technical progress.

b) Social financial constraint looseness fin. For the financing constraint in certain region, current scholars take different indexes in the empirical analysis. At present, most literatures represent financial development degree with the ratio of financial institutions' loan in that year to regional GDP; meanwhile, financial market index is also used (obtained by weighted index) to express the degree of financial constraint. Considering data availability, this paper selected the ratio of financial institutions' loan in that year to regional GDP to measure social financing constraint; the greater the index value is, more smaller social financing constraint will be.

This paper selected the provincial panel data of 31 provinces and cities in 1997-2014; the data of non-bank index variables all originated from the China Statistical Yearbook and Province Statistical Yearbook, bank structure and loan variable data come from China Financial Statistical Yearbook and Six Decades' Statistics Complication since New China.

\section{Measure Regression Result and Analysis}

The generalized moment method of panel data system is used to estimate formula (2) and (3), whose results are shown in Table 1. Table 1 is the analysis of influencing mechanism of banking market structure on industrial upgrading; according to the four lists of results, it can be seen that, banking market structure variable coefficients were significantly greater than 0 , which indicated that, that increased the proportion of non state-owned banks can promote industrial structural upgrading. According to the two cross terms, the two cross terms of technical progress are positive when applying statistics at the $10 \%$ probability level, and the two cross terms of loosening financing constraints are respectively 
Table 1. the analysis of influencing mechanism of banking market structure on industrial upgrading.

\begin{tabular}{ccccc}
\hline $\begin{array}{c}\text { Dependent } \\
\text { Variable }\end{array}$ & \multicolumn{2}{c}{$\begin{array}{c}\text { rationalization of industrial } \\
\text { structure }\end{array}$} & \multicolumn{2}{c}{$\begin{array}{c}\text { optimization of industrial structure } \\
\text { uis_ts }\end{array}$} \\
\hline row & $(1)$ & $(2)$ & $(3)$ & $(4)$ \\
\hline cluster & $2.520^{* * *}$ & $2.111^{* * *}$ & $6.014^{* * *}$ & $4.044^{* * *}$ \\
& $(0.000)$ & $(0.000)$ & $(0.001)$ & $(0.009)$ \\
tech×cluster & $0.109^{* *}$ & & $0.289^{*}$ & \\
& $(0.042)$ & & $(0.062)$ & \\
fin×cluster & & $-0.164^{* * *}$ & & $0.975^{* * *}$ \\
& & $(0.000)$ & & $(0.000)$ \\
urb & $-0.491^{* * *}$ & $-0.464^{* * *}$ & $-2.338^{* * *}$ & $-2.449^{* * *}$ \\
& $(0.000)$ & $(0.000)$ & $(0.000)$ & $(0.000)$ \\
open & 0.014 & 0.037 & $0.123^{*}$ & 0.017 \\
& $(0.584)$ & $(0.132)$ & $(0.098)$ & $(0.795)$ \\
lncom & $0.225^{* * *}$ & $0.206^{* * *}$ & $0.174^{*}$ & $0.291^{* * *}$ \\
Constant & $(0.000)$ & $(0.000)$ & $(0.083)$ & $(0.001)$ \\
term_cons & $-3.186^{* * *}$ & $-2.569^{* * *}$ & $5.008^{* * *}$ & 1.852 \\
AR(1)-prob & $(0.000)$ & $(0.000)$ & $(0.009)$ & $(0.263)$ \\
AR(2)-prob & 0.000 & 0.000 & 0.000 & 0.000 \\
Sargan test & 0.426 & 0.431 & 0.394 & 0.407 \\
$N$ & 0.000 & 0.000 & 0.000 & 0.000 \\
\hline & 497 & 497 & 497 & 497 \\
\hline
\end{tabular}

note: $(1){ }^{*},{ }^{* *},{ }^{* *}$ represent that at $10 \%, 5 \%, 1 \%$ level, the result is significantly positive.

negative and positive, but were higher than statistics, which indicated that changes in the banking market structure can promote rationalization and optimization of industrial structure; on the other hand, changes in the banking market structure can promote the upgrading of the industrial structure while inhibiting rationalization of industrial structure through the looseness of financing restraint. The three control variables showed that, the coefficients of urbanization rate was significantly lower than 0 in the four columns, the variation coefficient of openness and the level of per capita consumption were positive; meanwhile, the variables of per capita consumption were significantly positive.

Based on the above analysis, this paper concluded that, Chinese banking market structure positively influenced the rationalization and optimization of industrial structure, as a whole, banking market structure influenced the rationalization and optimization of industrial structure by technical progress and the looseness of financing constraints, among which the influence of technical progress is positive, looseness of financing constraints will inhibit the rationalization of industrial structure while can promote the optimization development of industrial structure. The influence mechanism on technological progress is the most obvious, the increase of non state-owned banks and commercial bank loans means the increase of social loans to commercial loans and small businesses; business and small enterprises usually carry the nature of science and technology pro- 
gress, such as information technology and entrepreneurial companies, which can promote industrial structural upgrading. The looseness of financing constraints is different in industrial structural rationalization and optimization. This paper considers that, the looseness of financing constraint is not only the increase of business enterprise loans increased, but also include the increase of industrial enterprise loans, although the development of the third industry can promote social and industrial upgrading, the manufacturing industry in recent years is improving product quality and introducing new products to promote business transformation; thus, in general, it can promote the optimization of the industrial structure.

\section{Conclusions and Policy Suggestion}

This paper selected the provincial panel data of 31 provinces and cities in 19972014. The demonstration tested the relationship between Chinese banking market structure and industrial structural upgrading; meanwhile, in the approaches of social technological progress and social financing constraints looseness, it analyzed whether the change of bank structure influences industrial structural upgrading through these two mechanisms. The research results showed that the increased proportion of non-state-owned banks in Chinese banking industry is not only conducive to the rational development of industrial structure, but also can promote the development of industrial structure. Banking structure will influence the rationalization and optimization of Chinese industrial structure via technological progress and financing constraints looseness. The influencing mechanism of technological progress is positive, but the looseness of financing constraints positively influence the optimization of industrial structure and generate a negative effect on the rationalization of industrial structure.

According to the research conclusion, we put forward the following suggestions:

1) To continue to our country banking industry reform, the introduction of private Banks and joint-stock Banks, increase the competitive banking system. This paper shows that the rise in the proportion of non-state bank can promote the upgrading of industrial structure, the country should speed up the banking sector reform, on the one hand it should guides state-owned Banks to increase the support of college students' innovative projects, micro, small and medium enterprises of the third industry. On the other hand, it should guide the social capital to the emerging industry of the third industry and secondary industry

2) Guide the social idle funds flow to the technology industry and financing constraints of serious enterprise. As the economic system tending to have the endogenous nature, that is, the original high technology industry and seriously financing constraints industry may be more likely to attract social idle capital inflows, therefore they have endogenous nature. Banks should pay more attention to the development of these industries, because these industries are more likely to become a good customer of the bank. At the same time, these industries are different from large enterprises which need wholesale funding, they often can 
survive only by a relatively small money, and science and technology enterprises growth better, and also can accelerate the technological innovation of the community as a whole.

3) Steadily improving our country's foreign open degree, improve the level of people's living consumption. National citizens should be encouraged to send deposit for consumption, therefore, in the proportion of consumption rise instead relies mainly on the investment structure of economic development in the past. Increase in consumption can also put forward a higher quality of enterprise products more performance requirements, thus reversed transmission enterprise transformation and upgrading. On the other hand, in order to import and export trade and GDP ratio measure improved growingly opened, also indicates that our country export commodities and increase imports. Export indicate commodities have a higher competitive advantage in our country, and imports represent greater competitive threat to domestic products, forcing enterprises to increase product research and development, the degree of opening to the outside world rise also is advantageous to the upgrading of industrial structure.

\section{References}

[1] Sun, J. and Li, H. (2012) Financial Aggregation and Industrial Structural Upgrading-Empirical Analysis of 2003-2007 Inter-Provincial Economics Data. Economist, No. 3, 80-89.

[2] Liu, P. and Yin, X. (2015) Banking Structure, Spatial Spillover and Industrial Structural Upgrading. Finance Evaluation, No. 1, 51-64.

[3] Liu, P. (2014) Spatial Effect of Banking Market Structure on Industrial Structural Optimization. Financial Economics Research, No. 3, 96-106.

[4] Gong, Q., Zhang, Y. and Lin, Y. (2014) Industrial Structure, Risk Characteristics and Optimal Financial Structure. Economic Research, No. 4, 4-16.

[5] Peng, Y.W., Zhang, M.T. and Mao, C. (2013) Relationship between Banking Market Structure and Economic Growth-Spatial Econometrics Research Based on Guangdong and Hunan Province. Economic Geography, No. 10, 108-116.

[6] Liu, N. (2014) Financial Structure, Banking Structure and Industrial Structural Upgrading. Financial Educational Research, 27, 15-23.

[7] Dong, L. and Shi, X. (2013) Calculation of Shanghai Three Times Industrial Technological Progress Level and Empirical Analysis of Its Influence on Employment: 1978-2011. Shanghai Economic Research, No. 5, 103-111.

[8] Sheng, X. and Hu, A.G. (2011) Empirical Analysis of Technological Progress on China Employment Human Capital Structure-Study of Panel Data Based on 29 Provinces. Science of Science and Science and Technology Management, No. 6, 172-179. 
Submit or recommend next manuscript to SCIRP and we will provide best service for you:

Accepting pre-submission inquiries through Email, Facebook, LinkedIn, Twitter, etc. A wide selection of journals (inclusive of 9 subjects, more than 200 journals)

Providing 24-hour high-quality service

User-friendly online submission system

Fair and swift peer-review system

Efficient typesetting and proofreading procedure

Display of the result of downloads and visits, as well as the number of cited articles Maximum dissemination of your research work

Submit your manuscript at: http://papersubmission.scirp.org/

Or contact jss@scirp.org 